\title{
Acute occlusion of the retinal arteries: current concepts and recent advances in diagnosis and management
}

\author{
S Beatty, K G Au Eong
}

\begin{abstract}
PurposelBackground-Central retinal artery occlusion (CRAO) is usually a blinding event, and is not an infrequent presentation to the accident and emergency $(A \& E)$ department. The evidencebase in support of current treatment options is weak.

Methods-This paper reviewed the literature germane to the diagnostic, therapeutic and prognostic aspects of retinal arterial occlusive disease.

Results-The visual prognosis associated with CRAO remains poor, and current therapeutic practices are of unproven benefit. The non-ophthalmologist in the A\&E department should lie the patient flat and give a stat dose of intravenous acetazolamide in an attempt to improve the retinal perfusion pressure.

Conclusion-The management of acute occlusion of the central retinal artery has not changed over the past 30 years, although the potential benefits of superselective intra-arterial fibrinolytic therapy warrant evaluation in a randomised controlled trial. The identification of underlying pathology is an essential component of medical care, and all cases should be followed up by an ophthalmologist because of the possibility of ocular rubeosis. (F Accid Emerg Med 2000;17:324-329)
\end{abstract}

Keywords: atheroma; embolus; fibrinolysis; retinal artery occlusion

Obstruction of the central retinal artery or its branches are not uncommon presentations to the accident and emergency (A\&E) department, and the combined incidence of central retinal artery occlusion (CRAO) and branch retinal artery occlusion (BRAO) lies between 0.5 and 1.5 per 1000 initial ophthalmical outpatient visits. ${ }^{1}$ The fundoscopic findings associated with occlusion of the central retinal artery were first described by von Graefe in 1859 , and there is little to add to his original account. $^{2}$ Obstruction of the retinal arterial circulation is an important clinical event not only in terms of the visual outcome and ophthalmical complications, but also because of the increased systemic morbidity and mortality among these patients. ${ }^{34}$ In this article we review the current literature germane to CRAO and BRAO, and discuss recent advances in diagnosis and management of this acute event.

\section{Pathophysiology}

ANATOMICAL CONSIDERATIONS

The retina receives its blood supply from two sources, both of which must be intact to maintain retinal function. The choriocapillaris of the choroid nurtures the outer retina, whereas the central retinal artery (CRA) and its end artery branches feed the inner retinal layers. These circulations both originate from the ophthalmic artery, the CRA being its first branch and the ciliary arteries giving rise to the choriocapillaris. Occasionally, a cilioretinal artery arises from the ciliary circulation and supplies a portion of the papillomacular bundle.

The central retinal artery enters the globe at the optic disc where it bifurcates into superior and inferior branches, each of which in turn bifurcates into nasal and temporal branch retinal arteries. Therefore, occlusion of the central retinal artery deprives the entire inner retina of its blood supply unless a cilioretinal artery is present (15-30\% of eyes). ${ }^{5}$

PATHOLOGICAL CONSIDERATIONS

Arterial occlusive disease of the retina is the result of either arteriosclerotic thrombosis, vasculitis, embolic impaction, vasospasm or systemic hypotension. Over $75 \%$ of patients with CRAO suffer from generalised atheromatous disease, which is frequently associated with hypertension or diabetes mellitus, or both. ${ }^{6}$ Narrowing of the arterial lumen is typically seen at the level of the lamina cribrosa, and a final thrombotic episode is believed to account for the acute obstruction. However, obliteration of the retinal arterial lumen is also seen in the systemic vasculitides, most notably giant cell arteritis where an embolism can arise from an inflamed proximal vessel. ${ }^{78}$

Retinal emboli may consist of a variety of materials including platelet aggregates, ${ }^{9}$ cholesterol, ${ }^{10}$ calcium, ${ }^{6}$ fat, ${ }^{11}$ parasites, air and even prosthetic heart valves. ${ }^{6}$ The plateletfibrin and cholesterol emboli typically arise from atheromatous plaques at the carotid bifurcation or the internal carotid artery, whereas calcific and septic emboli are usually of cardiac valvular origin. ${ }^{6}$

Evaluating the patient with acute occlusive disease of the retinal arterial circulation

HISTORY AND EXAMINATION

History

The visual symptoms associated with retinal artery occlusion depend on the vessel involved. Acute CRAO presents with a sudden, painless 
Table 1 Systemic and ocular conditions causally linked with retinal arterial occlusions

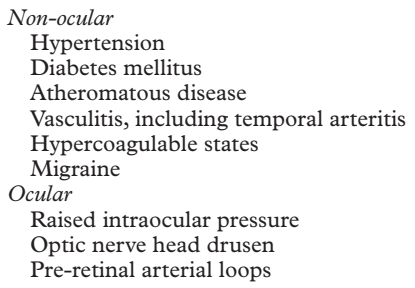

and profound drop in vision, usually with an initial Snellen acuity of counting fingers or worse, ${ }^{12}$ unless a cilioretinal artery is present in which case central vision may be preserved. Acute BRAO most commonly affects the temporal vessels, and the presenting visual acuity can vary from hand movements to $6 / 5 .^{13}$

A careful history aimed at identifying all aetiopathogenic mechanisms involved in the occlusive event should be taken. Particular attention should be directed to the presence of hypertension, ${ }^{341314}$ diabetes mellitus, ${ }^{3413}$ atherosclerotic cardiovascular and cerebrovascular disease ${ }^{34}$ and symptoms suggestive of giant cell arteritis. ${ }^{8}$ The clinician should also inquire after cigarette smoking, palpitations, valvular heart disease and a history of transient ischaemic attacks. ${ }^{15}$

In patients with a "negative" history, and particularly in subjects less than 40 years of age, other aetiological factors should be considered and these include systemic vasculitis, ${ }^{16}$ migraine, ${ }^{17}$ sickle cell haemoglobinopathy, ${ }^{17}$ myeloproliferative disorders, ${ }^{16}$ hypercoagulable states, ${ }^{17}$ use of oral contraceptives ${ }^{16}$ and intravenous drug abuse $^{17}$ (table 1).

\section{Ocular examination}

The ophthalmoscopic features of acute CRAO include a whitish, oedematous retina attributable to infarction, especially at the posterior pole where the nerve fibre layer and ganglion cell layer are thickest. As these layers are absent in the fovea, the underlying choroidal vascular bed can be seen in this area thus giving rise to the classic cherry-red spot (fig 1). In the presence of a patent cilioretinal artery, the retinal region served by the unobstructed vessel is not involved (fig 2). Disc pallor and retinal vascular

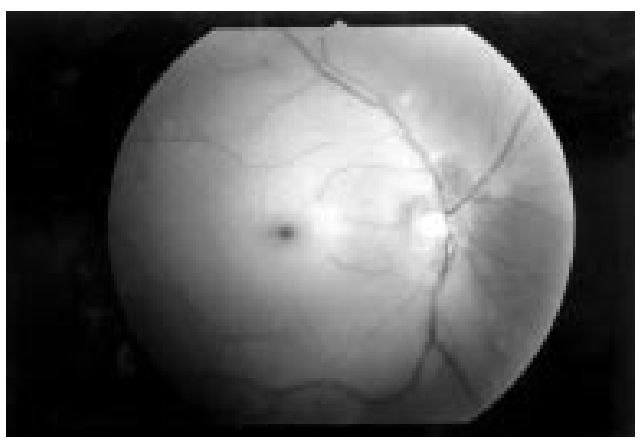

Figure 1 A right sided central retinal artery occlusion. Note the retinal whitening that is most obvious at the posterior pole, thus giving rise to the characteristic cherry-red spot at the fovea.

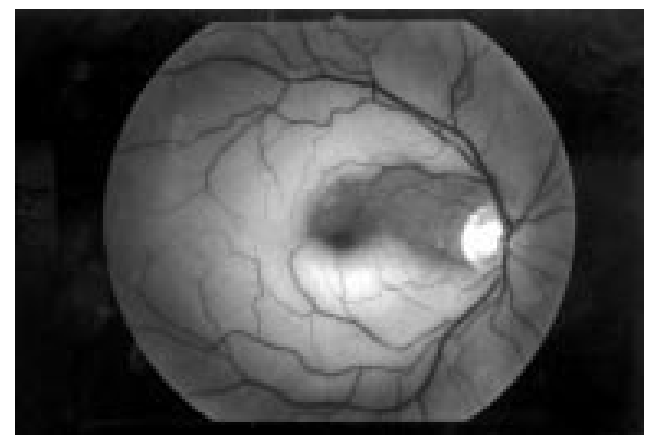

Figure 2 A right sided central retinal artery occlusion, but the superior macula is spared because of a patent cilioretinal artery serving that area. A cilioretinal artery is present in $15 \%$ to $30 \%$ of people.

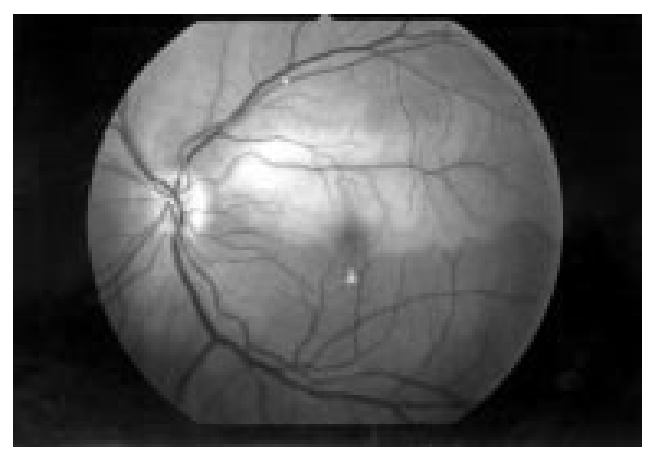

Figure 3 A left sided superotemporal branch retinal artery occlusion. Note the embolus at an arterial bifurcation in the same quadrant. Some exudates can be seen inferior to the macula, but these probably constitute an incidental finding.

narrowing are also characteristic of CRAO, although normal appearing retinal vessels do not rule out a complete occlusion of the central retinal artery. ${ }^{13}$ BRAO results in retinal oedema in the distribution of the affected vessel only (fig 3). Obstruction of a cilioretinal artery, or even a macular branch arteriole, gives rise to oedema of that region of the macula served by the occluded vessel and usually affects central vision.

Although a diagnosis of retinal arterial occlusion is usually obvious, a careful examination of the affected eye may provide important clues relating to aetiological factors. Ocular characterisitics causally linked with retinal artery occlusion include acutely raised intraocular pressure, ${ }^{17}$ pre-retinal arterial loops, ${ }^{17}{ }^{18}$ and drusen of the optic nerve head ${ }^{17}$ (table 1). The presence of hypertensive, diabetic or sickle cell retinopathy is suggestive of small vessel disease. The clinical and morphological appearance of retinal emboli can also be of diagnostic value. Cholesterol emboli, also known as Hollenhorst plaques, are small, yellow and refractile ${ }^{19}$ (fig 4). Calcific emboli are single, white and non-scintillating plaques located in the proximal retinal vasculature whereas fibrino-platelet emboli are small, pale bodies. ${ }^{15}{ }^{19}$ However, interobserver agreement with respect to the categorisation of retinal emboli is poor, ${ }^{20}$ and therefore a comprehensive systemic evaluation is indicated in all cases of acute obstruction of the retinal arteries $^{21}$ (table 2). 
Table 2 Investigations recommended in cases of central and branch retinal arterial occlusions

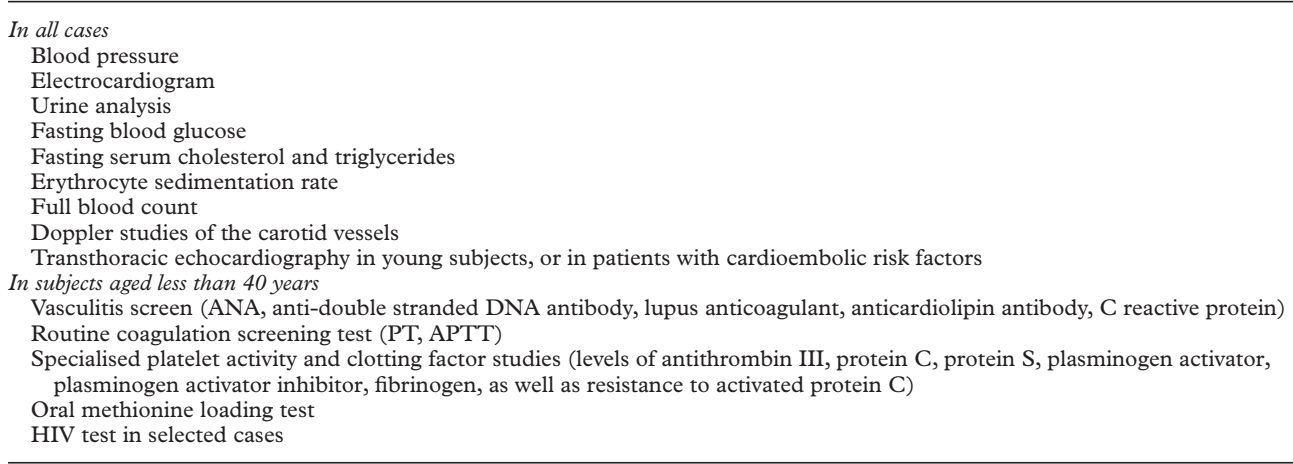

ANA: antinuclear antibody; PT: prothrombin time; APTT: activated partial thromboplastin time.

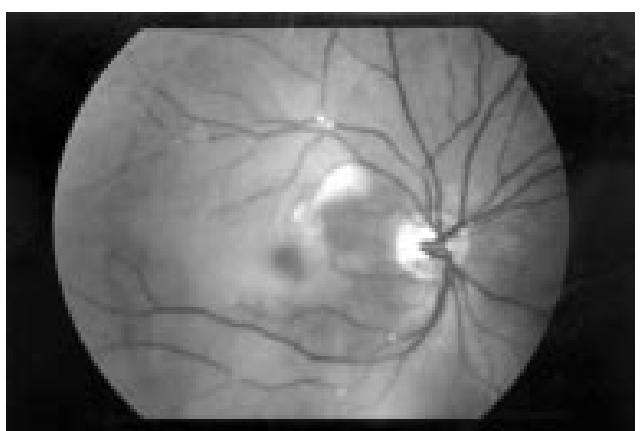

Figure 4 Multiple cholesterol emboli (Hollenhorst plaques) can be seen in the inferotemporal and superotemporal retinal arterial circulation. Retinal whitening and a cherry-red spot are also evident.

Non-ocular examination

The physical examination is directed toward the possible causes of the acute occlusive event and should include a complete cardiovascular assessment. Of particular interest is the rate and rhythm of the radial pulse, and the blood pressure. Auscultation is useful in the detection of carotid bruits and heart murmurs. If giant cell arteritis is a possibility, nodular temporal arteries and scalp tenderness should raise the clinician's index of suspicion. In the absence of an obvious cause of the retinal artery occlusion, especially in young patients, you should also be attentive for vasculitic rashes.

INVESTIGATIONS

Ophthalmical investigations

Fundus fluorescein angiography (FFA) is not routinely indicated in the acute phase of retinal arterial occlusive disease unless the diagnosis is in doubt. Angiographic findings associated with CRAO and BRAO include delayed filling of the affected vessels, reduced arterial calibre and "cattle-trucking" of the blood column in the branch arteries.

Systemic investigations

The following investigations are recommended in all cases of retinal artery occlusion: electrocardiography; urine analysis; fasting blood glucose; fasting blood cholesterol; fasting serum triglycerides; full blood count. An erythrocyte sedimentation rate and $\mathrm{C}$ reactive protein levels are justified in all cases to exclude giant cell arteritis.

In patients less than 40 years of age additional investigations are indicated to inves- tigate whether a vasculitic process or a hypercoagulable state has contributed to the occlusive event. Brown et al have found evidence of a coagulation disorder in one third of young patients with retinal artery occlusive disease. ${ }^{17}$ The mechanisms involved are complex and include thrombocytosis, ${ }^{17}$ an increase in coagulation factor or platelet activity, ${ }^{17}$ deficiencies of protein $\mathrm{C}$ and protein $\mathrm{S},{ }^{1622}$ resistance to activated protein $C,{ }^{23}$ and the interaction of lupus anticoagulant and anticardiolipin antibodies with phospholipids. ${ }^{16}$ Routine coagulation screening tests, including prothrombin time and partial thromboplastin time, as well as the more specialised platelet activity and coagulation factor studies are therefore indicated in unexplained retinal artery occlusions in young subjects. A screen for vasculitis should include the following: anticardiolipin antibodies ${ }^{24}$; antinuclear antibodies $^{15}$; anti-double stranded DNA antibodies. $^{24}$

Hyperhomocystinaemia has been reported in several patients with CRAO and BRAO ${ }^{25} 26$ and this is attributed to its toxic effect on the vascular endothelium. Consequently, in suspected homocystinuria or heterozygosity for homocystinuria an oral methionine loading test is recommended as hyperhomocysteinaemia can be successfully treated with appropriate vitamin supplements. ${ }^{27}$

Finally, and only if there are strong clinical indications, testing for human immunodeficiency virus (HIV) may be indicated, as retinal arterial occlusive disease has been described in young people with HIV infection. ${ }^{15} 28$

Doppler studies of the carotid arteries are recommended in all cases of CRAO and BRAO, as there is a reported $19 \%$ incidence of haemodynamically significant carotid artery stenosis among these patients. ${ }^{21}$ Transthoracic echocardiography should be performed in all young patients with occlusive disease of the retinal arteries, and in older patients with any of the following cardioembolic risk factors: subacute bacterial endocarditis; rheumatic heart disease; mitral valve prolapse; recent myocardial infarction; prosthetic valve; intravenous drug abuse; cardiac tumour; heart murmur; ECG abnormalities including atrial fibrillation, acute ST elevation and Q waves. $^{29}{ }^{30}$ Cardiac abnormalities detected by 


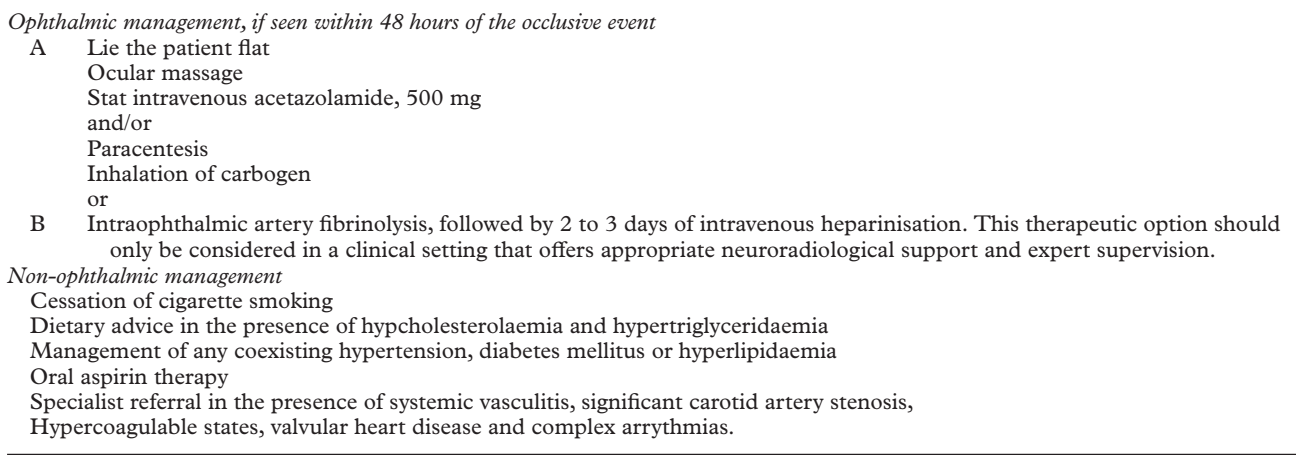

echocardiography in a series of 11 young patients with CRAO and BRAO included mitral valve thickening, left ventricular hypertrophy, thrombus with bicuspic aortic valve and mitral valve prolapse. ${ }^{29}$ Of these, three $(60 \%)$ required intervention in the form of anticoagulant therapy or cardiac surgery. ${ }^{29}$

\section{Acute ophthalmic management}

The variety of reported management options for CRAO and BRAO reflects the lack of a safe and efficacious treatment for this vascular occlusive event. The aim of treatment is to increase the perfusion pressure of the retinal circulation, or to dislodge or lyse the obstructing thrombus/embolus. Currently accepted practice in the management of acute CRAO or BRAO is dictated largely by the level of available expertise. For example, the nonophthalmologist in a general $A \& E$ department should lie the patient flat, give a stat dose of acetozolamide $(500 \mathrm{mg}$ ) intravenously, and instruct the patient to perform ocular massage. The ophthalmologist in the same environment may also wish to perform anterior chamber paracentesis. In a few centres, appropriate neuroradiological and ophthalmical support to consider selective intra-arterial fibrinolytic therapy may be available (table 3 ). The rationale and evidence base for these therapeutic approaches is discussed in this section.

The length of time the human retina can tolerate ischaemia before irreversible damage occurs remains uncertain. Although significant visual recovery has been reported up to 72 hours after the occlusive event, the visual prognosis tends to worsen with increasing duration of the visual symptoms. ${ }^{12}$ Hayreh et al reported on the reversibility of the fundoscopic, angiographic, electrophysiological and morphological findings after clamping of the CRA in 63 Rhesus monkeys, and concluded that the retinal tolerance time was approximately 100 minutes. ${ }^{31}$ However, it is probable that the degree of retinal ischaemia induced by clamping of the central retinal artery is greater than in the clinical setting as filling of the arterial system, albeit delayed, is seen on FFA in cases of CRAO.

INCREASING THE RETINAL PERFUSION PRESSURE The perfusion pressure of the retinal circulation can be increased by one of the following mechanisms: reducing intraocular pressure
(IOP); dilating the ophthalmic and central retinal arteries; increasing the ophthalmic artery pressure.

\section{Reducing IOP}

The combination of ocular massage and intravenous acetazolamide $(500 \mathrm{mg})$ can achieve an IOP as low as $5 \mathrm{~mm} \mathrm{Hg}$ within a short period of time, and is probably the most widespread form of treatment for cases of CRAO and BRAO that present within the acute stage. ${ }^{6}$ Ocular massage is achieved by asking the patient to digitally apply pressure to the globe throught the closeed eyelids of the affected eye for a period of 15 to 30 minutes. The importance of ocular massage and intravenous acetozolamide rests on the fact that these steps can be undertaken by non-ophthalmic staff of the A\&E department.

The role of anterior chamber paracentesis is, however, more controversial. This is achieved by inserting a 27 gauge needle into the anterior chamber via the limbus and withdrawing 0.1 to $0.2 \mathrm{ml}$ of aqueous fluid. Paracentesis falls within the remit of the ophthalmologist, as it is an intraocular procedure, and should never be attempted by non-ophthalmic staff of the $A \& E$ department. The potential benefits of paracentesis include a dramatic drop in IOP, and dilatation of the retinal arteries because of the vascular tortuosity resulting from distortion of the globe. ${ }^{32}$ However, a maximum increase in retinal arterial volume flow of only $20 \%$ has been estimated from animal studies, and a rise in perfusion pressure of less than $15 \%$ is expected when the IOP falls from $15 \mathrm{~mm} \mathrm{Hg}$ to $5 \mathrm{~mm}$ $\mathrm{Hg}$. In addition to a lack of clinical efficacy, ${ }^{33}$ other factors that discourage ophthalmologists from performing paracentesis in cases of CRAO include the risk of complications and the need to repeat the procedure on a two hourly basis to maintain the low IOP.

Dilating the ophthalmic and retinal arteries Several techniques to induce retinal arterial vasodilatation have been reported and these include ocular massage ${ }^{6}$ retrobulbar administration of vasodilator drugs ${ }^{634}$ and inhalation of carbogen. ${ }^{35}$ In addition to reducing the IOP, ocular massage can increase the retinal arterial flow volume by $180 \%$ as a result of the vasodilatation that occurs on release of digital pressure. ${ }^{6}$ A small rise in ophthalmic artery pressure, which will also influence retinal 
perfusion pressure in a favourable way, is achieved by lying the patient flat. ${ }^{6}$ Retrobulbar injections of vasodilator drugs and the inhalation of carbogen are of doubtful clinical benefit, and are therefore not in widespread use. $^{633}$

DISLODGING THE THROMBUS/EMBOLUS

Ocular massage is known to cause retinal arterial dilatation and large fluctuations in IOP. It has been postulated that this activity may mechanically facilitate the disintegration of a thrombus, or dislodge an impacted embolus into a more peripheral part of the retinal circulation.

LYSING THE THROMBUS/EMBOLUS

The limited success, ${ }^{36}$ and risk of intracerebral haemorrhage, ${ }^{37}$ associated with systemic administration of thrombolytic agents for CRAO has resulted in its discontinuation in favour of selective intra-arterial fibrinolytic therapy.

\section{Selective intra-arterial fibrinolytic therapy}

Considerable success has been reported after injection of urokinase or tissue plasminogen activator (TPA) into the ophthalmic artery via a microcatheter in cases of CRAO. ${ }^{38} 39$ However, the practice of selective intra-arterial fibrinoysis is not widespread as specialist neuroradiological support is required and serious complications can occur.

In a recent meta-analysis, we have reported a final visual acuity of $6 / 12$ or better in $27 \%$ of subjects after selective intra-arterial fibrinolytic therapy for CRAO compared with $18 \%$ to $21 \%$ for conventional approaches. ${ }^{12}{ }^{40}{ }^{41}$ Also, a poor visual outcome of $3 / 60$ or worse was seen in $60.6 \%$ of eyes treated with intra-arterial fibrinolytic therapy, and this compares with $62.5 \%$ to $66 \%$ for conservative treatment modalities. ${ }^{12} 42$ It seems, therefore, that this treatment may be of marginal benefit. Should the visual results improve with advances in neuroradiological techniques, this treatment option is likely to become increasingly available. We believe that a substantial proportion of patients would consent to undergo this emergency procedure as a recent survey has shown that $37 \%$ of binocular adults with CRAO would risk a cerebrovascular accident or death to triple their chances of recovering a visual acuity of $6 / 36$ or better in one eye, and this rose to $80 \%$ for monocular subjects. ${ }^{43}$

SYSTEMIC ANTICOAGULATION

After regional thrombolytic therapy for CRAO, intravenous heparin is administered for two to three days. The value of therapeutic heparinisation alone in this group of patients remains uncertain. ${ }^{44}$ Recently Liu et al have reported an improvement in retinal function, as evaluated by electroretinography, in rats after temporary occlusion of the CRA using certain coumarin derivatives. ${ }^{45}$ However, the clinical application of these findings has yet to be investigated.

SYSTEMIC ANTIPLATELET THERAPY

To our knowledge, the value of oral aspirin after CRAO and BRAO has not been investi- gated. However, in the absence of contraindications, it seems clinically prudent to prescribe this antiplatelet drug in an attempt to reduce the risk of further thrombotic occlusive events affecting the retina and other organs.

\section{Ophthalmic follow up}

Although the visual acuity is unlikely to improve more than one week after an acute obstruction of a retinal artery, follow up by an ophthalmologist is essential because of possible retinal and iris neovascularisation. The pathogenesis of ocular neovascularisation after these acute vascular occlusive events remains poorly understood, but there is a general consensus that chronic retinal ischaemia plays an important aetiological part. ${ }^{46}$ The incidence of ocular neovascularisation after CRAO lies between $16.6 \%$ and $18.75 \%$, and the majority of these go on to develop rubeotic glaucoma $(67.5 \%$ to $83.3 \%)^{47-49}$ The time interval between the occlusive event and the development of neovascularisation ranges from 10 days to 10 months, but the vast majority occur within three months of the arterial obstruction. ${ }^{49}$ Panretinal photocoagulation has been shown to reduce the risk of rubeotic glaucoma and a painful eye, and close ophthalmic follow up is therefore recommended for a minimum period of three months after the occlusive event. ${ }^{47}$

\section{Non-ophthalmic follow up}

Systemic management in cases of CRAO and BRAO is aimed at reducing morbidity and mortality associated with predisposing and related conditions. Measures recommended in all cases include cessation of smoking, appropriate dietary advice, managing blood pressure and oral aspirin therapy. Otherwise, associated disorders should be treated on their own merits, and specialist referral is indicated in the presence of systemic vasculitis, significant carotid artery stenosis, hypercoagulable states, valvular heart disease and complex arrythmias (table 3).

\section{Prognosis}

VISUAL PROGNOSIS

In those eyes where the macula is not served by a cilioretinal artery, the visual outcome after obstruction of the central retinal artery is generally poor. CRAO is associated with a poor final acuity of counting fingers or worse in $62.5 \%$ to $66 \%$ of cases, and with a good final acuity of $6 / 12$ or better in $18 \%$ to $21 \%$ of affected eyes. ${ }^{12}{ }^{42}$ The visual outcome is related to the presenting acuity and the duration of visual impairment, ${ }^{12}$ and seems to be improved in patients receiving intra-arterial fibrinolytic therapy.

\section{SYSTEMIC PROGNOSIS}

The most common cause of death in subjects who have suffered acute occlusive events of the retinal arteries is cardiovascular disease. ${ }^{34}$ Although the survival prognosis for this entire group of patients is statistically comparable to age and sex matched controls, the subgroup with visible retinal emboli do have a significantly shorter life expectancy. ${ }^{350}$ Of the 152 
patients with retinal arterial obstructions reported by De Potter and Zografos, 26\% died during a mean period of follow up of 9.7 years. $^{50}$

\section{Conclusion}

Sudden loss of vision is a common presentation to the A\&E department, and acute occlusive events of the retinal arterial circulation account for a substantial proportion of cases. All patients with CRAO or BRAO should be appropriately investigated, and particular attention should be directed to the possibility of conditions that require immediate treatment such as giant cell arteritis. A variety of therapeutic options are available in the acute phase, none of which are of proven benefit. In all cases, ophthalmological advice is indicated regarding acute management and follow up.

Contributors

Stephen Beatty saw a need to review the current evidence germane to diagnostic and therapeutic aspects of retinal arterial occlusive disease, initiated this project, and was the principal author of the paper. Kah-Guan Au Eong discussed core ideas, provided constructive criticism and contributed to the editorial design of the review article. The guarantor of the paper is Stephen Beatty, Clinical Lecturer in Ophthalmology, Manchester Royal Eye Hospital.

Funding: none.

Conflicts of interest: none.

1 Karjalainen $\mathrm{K}$. Occlusion of the central retinal artery and retinal branch arterioles. Acta Ophthalmol 1971;109 (suppl): 1-96

2 Von Graefe A. Ueber Embolie der Arteria centralis retinae als Ursache plotzlicher erblindung. Albrecht von Graefe's Arch Ophthalmol 1859;5:136-85.

3 Savino PJ, Glaser JS, Cassady J. Retinal stroke. Is the patient at risk? Arch Ophthalmol 1977;95:1185-9.

4 Pfaffenbach DD, Hollenhorst RW. Morbidity and survivorship of patients with embolic cholesterol crystalization in the ocular fundus. Am $\mathcal{F}$ Ophthalmol 1973;75:66-72.

5 Lorentzen SE. Incidence of cilioretinal arteries. Acta Ophthalmol (Copenh) 1970;48:518-24.

6 ffytche TJ. A rationalization of treatment of central retinal artery occlusion. Trans Ophthalmol Soc UK 1974;94:46879 .

7 Fineman MS, Savino PJ, Federman JL, et al. Branch retinal artery occlusion as the initial sign of giant cell arteritis. $A m$ f Ophthalmol 1996;122:428-30.

8 Wang FM, Henkind P. Visual system involvement in giant cell (temporal) arteritis. Surv Ophthalmol 1979;32:254-71

9 McBrien DJ, Bradley RD, Ashton N. The nature of retinal emboli in stenosis of the internal carotid artery. Lancet 1963;i:697-9.

10 David NJ, Klintworth GK, Friedberg SJ. Fatal atheromatous cerebral embolism associated with bright plaques in the retinal circulation. Neurology 1963;9:333-47.

11 Cogan DG, Kuwabara T, Moser H. Fat emboli in the retina following angiography. Arch Ophthalmol 1964;71:308-13.

12 Augsburger JJ, Magargal LE. Visual prognosis following treatment of acute central retinal artery obstruction. $B r \mathcal{F}$ Ophthalmol 1980;64:913-17.

13 Ros MA, Magargal LE, Uram M. Branch retinal-artery obstruction: A review of 201 eyes. Ann Ophthalmol obstruction: A

14 Appen RE, Wray SH, Cogan DG. Central retinal artery occlusion. Am f Ophthalmol 1975;79:374-81.

15 Graham EM. The investigation of patients with retinal vascular occlusion. Eye 1990;4:464-8.

16 Greven GM, Slusher MM, Weaver RG. Retinal arterial occlusions in young adults. Am $\mathcal{F}$ Ophthalmol 1995;120 776-83.

17 Brown GC, Magargal LE, Shields JA, et al. Retinal arterial obstruction in children and young adults. Ophthalmology 1981;88:18-25.

18 Brown GC, Magargal L, Augsburger JJ, et al. Preretinal arterial loops and retinal artrial occlusion. Am f Ophthalmol 1979;87:646-51.

19 Russel RW. The source of retinal emboli. Lancet 1968;ii: 789-92.

20 Sharma S, ten Hove MW, Pinkerton RMH, et al. Interobserver agreement in the evaluation of acute retinal Interobserver agreement in the evaluation of acute

21 Sharma S. The systemic evaluation of acute retinal artery occlusion. Current Opinion in Ophthalmology 1998;9:1-5.

22 Comp PC, Esmon CT. Recurrent venous thromboembolism in patients with a partial deficiency of protein S. $N$ Engl f Med 1984;311:1525-8.
23 Vignes S, Wechsler B, Elmaleh C, et al. Retinal arterial cclusion associated with resistance to activated protein $\mathrm{C}$. Br f Ophthalmol 1996;80:1111.

24 Love PE, Santoro SA. Antiphospholipid antibodies: anticardiolipin and the lupus anticoagulant in systemic lupus erythematosus (SLE) and in non-SLE disorders. Prevalence and clinical significance. Ann Intern Med 1990;112:682-98.

25 Wenzler EM, Rademakers AJJM, Boers GHJ, et al. Hyperhomocysteinemia in retinal artery and retinal vein occlusion. Am f Ophthalmol 1993;115:162-7.

26 Wilson RS, Ruiiz RS. Bilateral central retinal artery occlusion in homocystinuria. Arch Ophthalmol 1969;82: 267-8.

27 Boers GHJ, Smals AGH, Trijbels FJM, et al. Heterozyogosity for homocystinuria in premature peripheral and cerebral occlusive arterial disease. $N$ Engl f Med 1985;709: 313-19.

28 Conway $\mathrm{MD}$, Tong $\mathrm{P}$, Olk AJ. Branch retinal artery occlusion (BRAO) combined with branch retinal vein occlusion (BRVO) and optic disc neovascularization associated with HIV and CMV retinitis. Int Ophthalmol 1995-1996;19:249-52.

29 Sharma S, Naqvi A, Sharma SM, et al, for the RECO study group. Transthoracic echocardiographic findings in patients with acute retinal arterial obstruction. Arch Ophthalmol 1996;114:1189-92.

30 Sharma S, Sharma SM, Cruess AF, et al, for the RECO study group. Transthoracic echocardiography in young patients with acute retinal arterial obstruction. Can f Ophthalmol 1997;32:38-41.

31 Hayreh SS, Kolder HE, Weingeist TA. Central retinal artery occlusion and retinal tolerance time. Ophthalmology 1980; 87:75-8.

32 ffytche TJ, Bulpitt CJ, Kohner EM, et al. Effect of changes in intraocular pressure on the retinal microcirculation. $\mathrm{Br} f$ Ophthalmol 1974;58:514-22.

33 Atebara NH, Brown GC, Cater J. Efficacy of anterior chamber paracentesis and carbogen in treating acute nonarteritic central retinal artery occlusion. Ophthalology 1995;102: 2029-35.

34 Gombos GM. Retinal vascular occlusions and their tratment with low molecular weight dextran and vasodilators: report of six years' experience. Ann Ophthalmol 1978;10:579-83.

35 Tsacopoulos M, David NJ. The effect of arterial PCO2 on relative retinal blood flow in monkeys. Invest Ophthalmol 1973;12:335-45.

36 Bertram B, Wolf S, Fisches H, et al. Thrombolytic treatment of retinal arterial occlusions with plasminogen activator. Klin Monatsbl Augenheilkd 1991;198:295-300.

37 Barth H, Stein H, Fasse A, et al. Intracerebral haemorrhage after systemic thrombolysis in patients with occlusion of the central retinal artery. Report of two cases. Ophthalmologe 1996;93:739-44.

38 Schmidt D, Schumacher M, Wakhloo AK. Microcatheter urokinase infusion in central retinal artery occlusion. Am $\mathcal{f}$ Ophthalmol 1992;113:429-34.

39 Zeumer H, Freitag H-J, Grzyska U, et al. Local intraarterial fibrinolysis in acute vertebrobasilar occlusion. Technical developments and recent results. Neuroradiology 1989;31: $336-42$

40 Vulpius K, Hoh H, Lange H, et al. Seletive perkutane transluminale Lysetherapie mit RTPA bei retinalem Zentralarterienverschluss. Ophthalmologe 1996;93:149-53.

41 Beatty S, Au Eong KG. Selective intra-arterial fibrinolytic therapy for central retinal artery occlusion: a meta-analysis. $B r \mathcal{F}$ Ophthalmol (in press)

42 Brown GC, Magargal LE. Central retinal artery obstruction and visual acuity. Ophthalmology 1982;89:14-19.

43 Margo CE, Mack WP. Therapeutic decisions involving disparate clinical outcomes. Patient preference survey for treatment of central retinal artery occlusion. Ophthalmology 1996;103:691-6.

44 van den Berg E, Lohmann N, Friedburg D, et al. Report of general temporary anticoagulation in the treatment of acute cerebral and retinal ischaemia. Vasa 1997;26:222-7.

45 Liu SX, Kapingu MC, Wang MS, et al. Facilitation of retinal function recovery by coumarin derivatives. $\mathcal{F}$ Ocul Pharmacol Ther 1997;13:69-79.

46 Laatidainen L. Preliminary report on effect of retinal panphotocoagulation on rubeosis iridis and neovascular glaucoma. Br f Ophthalmol 1977;61:278-84.

47 Duker JS, Brown GC. The efficacy of panretinal photocoagulation for neovascularization of the iris after central retinal artery obstruction. Ophthalmology 1989;96:92-5.

48 Duker JS, Sivalingam A, Brown GC, et al. A prospective study of acute central retinal artery obstruction. Arch Ophthalmol 1991;109:339-42.

49 Hayreh SS, Podhajsky P. Ocular neovascularization with retinal vascular occlusion. Occurrence in central and branch retinal artery occlusion. Arch Ophthalmol 1982;100: 1585-96.

50 De Potter P, Zografos L. Survival prognosis of patients with retinal artery occlusion and associated carotid artery disease. Graefe's Arch Clin Exp Ophthalmol 1993;231:21216. 